\title{
The effect of pectin on the structure and function of the rat small intestine
}

\author{
BY R. C. BROWN, J. KELLEHER AND M. S. LOSOWSKY \\ Department of Medicine, St James's (University) Hospital, Leeds LS9 $7 T F$
}

(Received 8 March 1979 - Accepted 9 May 1979)

1. The effect of pectin on the structure and function of the rat small intestine was compared with that of a standard pellet diet and of a fibre-free basal diet.

2. The length and wet weight of the small bowel was significantly greater inpect in-fed rats than in either pellet- or basal-diet-fed rats.

3. Histological measurements of longitudinal sections from the small bowel showed a significantly greater crypt depth and muscle layer thickness in the mid-jejunum and ileum of the pectin fed rats. Villous height showed less variation.

4. The specific activity of alkaline phosphatase $(E C 3.1 .3 .1)$ and leucyl- $\beta$-naphthylamidase $(E C$ 3.4. I I I ) in mucosal scrapings was significantly lower in the upper jejunum of pectin-fed rats compared with either of the other dietary groups. The differences were not so marked in mid-jejunum or ileum.

5. Glucose absorption measured in vivo from jejunal and ileal loops was similar in all three dietary groups.

6. With two minor exceptions there were no significant differences in any of these measurements between the pellet- and basal-diet-fed rats.

7. These findings could be explained by increased epithelial cell turnover caused by pectin. The possible mechanisms of this are discussed.

8. The effect of pectin on the human small bowel requires study before it can be widely prescribed in man.

There is increasing interest in both the physiological and pharmacological effects of dietary fibre. Pectin, a partially methoxylated polymer of galacturonic acid is one form of dietary fibre attracting particular attention, as it seems to have the most consistent hypocholesterolaemic effect of all forms of fibre so far tested in man (Truswell, 1977). How pectin acts as a hypocholesterolaemic agent is unclear, but it may be by interfering with cholesterol absorption (Leveille \& Sauberlich, 1966). Subjects taking pectin show an increase in their faecal neutral steroid excretion as well as increased bile acid and faecal fat excretion (Kay \& Truswell, I977). If pectin, or other similar plant materials, are to be used pharmacologically, then more information is required about their effects both on the bowel itself and on the absorption of nutrients and drugs.

Pectin-fed rats excrete an oral dose of paracetamol more rapidly than rats on a fibrefree diet, the difference being due to more rapid absorption of paracetamol from the small bowel (Brown et al. 1979). The present paper describes studies of the small intestine of rats fed on a pectin diet compared with rats given either a fibre-free diet or a standard pelleted diet. Changes in intestinal anatomy have been quantitated, functional changes have been assessed by measuring in vivo glucose absorption from small bowel loops and biochemical changes have been assessed by measuring mucosal protein and DNA, and the activity of two brush border enzymes, alkaline phosphatase $(E C$ 3.I.3.I) and leucyl- $\beta$-naphthylamidase (EC 3.4. I I . I).

\section{MATERIALS AND METHODS}

Animals

Female Wistar rats, initial weight $175^{-220} \mathrm{~g}$ were used. 


\section{Caging}

The rats were housed in cages with wire-mesh floors, thus eliminating contact with bedding material.

\section{Diets}

Groups of six rats were given one of three diets, made up as follows: basal diet $(\mathrm{g} / \mathrm{kg})$ contained 750 sucrose, 150 casein, 50 lard, 50 salts mixture with added vitamins; pectin diet consisted of $\mathrm{I} 80 \mathrm{~g}$ citrus pectin (Bulmer's N.F. Pure; H. P. Bulmer, Hereford) added $/ \mathrm{kg}$ basal diet; pellet diet was Diet 4I B (Oxoid Ltd, 20 Southwark Bridge Road, London SEI $9 \mathrm{HF}$ ).

Groups were initially matched for weight. The pectin-fed group had the lowest weight gain, and the diet intake of the other two groups was adjusted twice weekly to give equal weight gain in all three groups.

\section{Operative procedure}

After 12-15 weeks on the diet, animals were taken in random order from the three groups. Laparotomy was performed on non-fasting animals under diethyl ether anaesthesia, and the small bowel measured and segmented into five lengths. These segments of bowel were measured in vivo so there was inevitably some variation between rats in their exact length. The five segments were as follows: a, upper jejunum (approximately $150 \mathrm{~mm}$ ) for morphology and biochemistry; b, 'jejunal' loop (approximately $250 \mathrm{~mm}$ ) for glucose perfusion; c, mid-jejunum for morphology and biochemistry (as the total length of the small bowel differed in the three groups the length of this segment was variable); $d$, 'ileal' loop (approximately $250 \mathrm{~mm}$ ) for glucose perfusion; e, terminal ileum (approximately $100 \mathrm{~mm}$ ) for morphology and biochemistry.

Proximal and distal cannulas were inserted into segments $b$ and $d$ for glucose perfusion (see p. 358) and the laparotomy closed. Rectal temperature was maintained at $37^{\circ}$ throughout with the aid of overhead lights.

\section{Glucose absorption}

Glucose absorption was measured by a modification of the in vivo recirculation perfusion system of Sheff \& Smyth (1955). After insertion of cannulas into segments b and $d$ the bowel was flushed clear of any food residue using Krebs-Ringer bicarbonate buffer at $37^{\circ}$ (Krebs \& Henseleit, I932). The animal was allowed to recover from anaesthesia in a restraining cage for $\mathrm{I} h$. During this period Krebs-Ringer bicarbonate buffer at $37^{\circ}$ was perfused through the segments at a rate of $1.5 \mathrm{ml} / \mathrm{min}$ for $55 \mathrm{~min}$, and the bowel then flushed with air. Glucose absorption was measured from a solution of glucose $(380 \mathrm{mg} /$ $100 \mathrm{ml}, 21 \mathrm{mmol} / \mathrm{l}$ ) and polyethylene glycol 4000 (PEG, $1.25 \mathrm{~g} / 100 \mathrm{ml}$ ) in Krebs-Ringer bicarbonate buffer. The mixture was circulated by pump from a $40 \mathrm{ml}$ reservoir at a rate of $1.5 \mathrm{ml} / \mathrm{min}$. Samples $(1.0 \mathrm{ml})$ were taken from the reservoir at zero time and at $10 \mathrm{~min}$ intervals thereafter for measurement of glucose, and an additional $0.5 \mathrm{ml}$ was taken after zero, 20 and 80 min of perfusion for measurement of PEG by the method of Hyden ( 1956 ). The glucose concentration was corrected for fluid transfer using the PEG concentrations and the amount of glucose absorbed/h calculated from the corrected glucose concentrations at 20 and $80 \mathrm{~min}$. Glucose absorption is expressed as $\mu \mathrm{mol} / \mathrm{mm}$ per $\mathrm{h}$.

\section{Intestinal anatomy}

After the glucose perfusions the animals were again anaesthetized with diethyl ether before removal of the intestine. The stomach, small bowel and colon as far as the rectum were removed. Adherent fat and mesentery were detached and the organs opened, washed and 
blotted dry with paper tissue before weighing. The small bowel was divided into the five segments described previously and the length of each individual segment measured against a vertical scale with the segment stretched by a $5 \mathrm{~g}$ weight.

Histology sections were cut from the proximal $10 \mathrm{~mm}$ of bowel of segments $\mathrm{a}, \mathrm{c}$ and $\mathrm{e}$. Well-orientated longitudinal sections, stained with haematoxylin and eosin were projected at a known magnification. The sections were coded before projection so that the origin of the section was unknown to the observer. The mean of five observations of total small bowel wall thickness, muscle layer thickness, mucosal thickness and crypt depth was calculated for each section.

\section{Mucosal biochemistry}

The remaining bowel from segments $a, c$ and $e$ was washed twice with ice-cold saline ( 9 g sodium chloride/1), and its mucosa then scraped off with a glass slide, and immediately homogenized in $10 \mathrm{ml}$ ice-cold normal saline/g tissue, using a motor-driven Potter-Elvehjem homogenizer with a Teflon pestle and glass vessel. The homogenate was stored at $-20^{\circ}$ until assayed. Mucosal DNA was measured by the method of Hatcher \& Goldstein (1969), mucosal protein by the method of Lowry et al. (195I) and mucosal alkaline phosphatase (EC 3.I.3.I) and leucyl- $\beta$-naphthylamidase ( $E C_{3.4}$. I I. I) by the method of Peters et al. (1972).

\section{Statistical analysis}

Values are given as mean values with their standard errors. Comparisons between the dietary groups were made using an unpaired Student's $t$ test.

\section{RESULTS}

\section{Diet intake and body-weight}

Mean daily consumption per rat was $15.7 \mathrm{~g}$ pectin diet, $13.0 \mathrm{~g}$ basal diet and $15.5 \mathrm{~g}$ pellet diet. The consumption of diet of the latter two groups was adjusted so that body-weights of these animals matched those of the pectin-fed group. Mean daily protein intake $(\mathrm{g} / \mathrm{rat})$ was pectin diet $1 \cdot 93$, basal diet $1 \cdot 95$, pellet diet $2 \cdot 03$.

Initial mean ( $\pm \mathrm{SE})$ body-weights $(\mathrm{g})$ for pectin, basal- and pellet-diet groups were $198 \pm 5,197 \pm 6$ and $198 \pm 6$ respectively. Final mean body-weights $(\mathrm{g})$ were $229 \pm 9,236 \pm 6$ and $234 \pm 5$ respectively. There was no significant difference between the body-weights of the groups at the beginning or end of the experiment.

\section{Small-bowel anatomy}

The total length of small bowel was significantly greater in pectin-fed rats than in either basal- or pellet-diet rats $(P<0.001$ and $P<0.05$ respectively). There was no significant difference between the basal- and pellet-diet groups. As was intended, the lengths of the measured segments (segments $a, b, d$ and e) were similar. Though segment $d$ was significantly longer in basal-diet-fed rats, the difference was small (Table r).

The wet weights of segments a, $\mathrm{c}$ and $\mathrm{e}$ of small bowel from pectin-diet-fed rats was greater than those from either basal- or pellet-diet-fed rats, the difference being most marked in segments $\mathrm{c}$ and $\mathrm{e}$ (Table 2). The weight of mucosal scrapings was also greater in all three segments in the pectin-fed rats, although these differences were not all statistically significant. There were no significant differences in either measurement between basal- and pellet-diet-fed rats. 
Table I. Length $(\mathrm{mm})$ of five individual intestinal segments $\dagger$ and the total length of small bowel in three groups of rats fed on a basal, pectin or pellet diet $\$$

(Mean values with their standard errors for groups of six rats for basal and pectin diets and of five rats for the pellet diet)

\begin{tabular}{|c|c|c|c|c|c|c|}
\hline \multirow{2}{*}{$\begin{array}{l}\text { Diet } \ldots \\
\text { Segment }\end{array}$} & \multicolumn{2}{|c|}{ Basal } & \multicolumn{2}{|c|}{ Pectin } & \multicolumn{2}{|c|}{ Pellet } \\
\hline & Mean & SE & Mean & SE & Mean & SE \\
\hline $\mathbf{a}$ & 142 & 7 & $12 \mathrm{I}$ & 15 & 172 & 33 \\
\hline b & 285 & 8 & 294 & 12 & 279 & 16 \\
\hline $\mathrm{c}$ & $19 \mathrm{I}$ & $20 * * *$ & 343 & 40 & 228 & $36^{* *}$ \\
\hline d & 252 & $7^{* * *}$ & 227 & 4 & 232 & 8 \\
\hline $\mathrm{e}$ & I 17 & 9 & III & I & 115 & II \\
\hline Total & 988 & $18^{* * *}$ & 1102 & 14 & 1026 & $34^{* * *}$ \\
\hline
\end{tabular}

Differences between either the basal- or pellet-diet-fed groups and the pectin-fed group were statistically significant: $* * * P<0.005$.

$\dagger$ For details, see p. 358.

$\$$ For details, see p. 358 .

Table 2. Wet weight of intestinal segments $(\mathrm{mg} / \mathrm{mm}$ length), and of mucosal scrapings $(\mathrm{mg} / \mathrm{mm}$ length) in three groups of rats fed on a basal, pectin or pellet diet $\dagger$

(Mean values with their standard errors for groups of six rats for basal and pectin diets and five rats for the pellet diet)

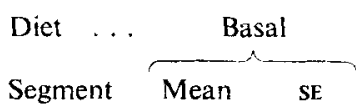

$\begin{array}{lll}\text { a } & 4.89 & 0.29 \\ \text { c } & 5.34 & 0.52^{*} \\ \text { e } & 4.18 & 0.52^{*}\end{array}$

$\begin{array}{lll}\text { a } & 2.24 & 0.21^{*} \\ \mathrm{c} & 2.42 & 0.16^{* *} \\ \mathrm{e} & 1.56 & 0.18^{*}\end{array}$

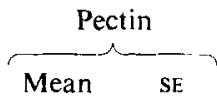

Segment wt

$5.22 \quad 0.2$

$6.76 \quad 0.26$

$5.95 \quad 0.40$

Mucosal wt

$2.77 \quad 0.12$

$3.21 \quad 0.15$

$2.08 \quad 0.20$

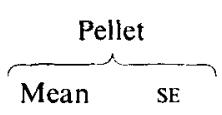

$4 \cdot 78 \quad 0.46$

$5.12 \quad 0.30^{* * *}$

$3.95 \quad 0.23^{* * *}$

$\begin{array}{ll}2 \cdot 10 & 0.15^{* * *} \\ 2.70 & 0.32 \\ 1.82 & 0.25\end{array}$

Differences between either the basal- or pellet-diet-fed groups and the pectin-fed group were statistically significant: * $P<0.05,{ }^{* *} P<0.01,{ }^{* * *} P<0.005$.

$\dagger$ For details, see p. 358 .

\section{Histological measurements}

The total thickness of the small bowel wall in the three dietary groups was similar in segment a, but was significantly greater in the pectin-fed rats in both segments $\mathrm{c}$ and $\mathrm{e}$ (Table 3 ).

This difference in segments $c$ and e arose partly from a greater muscle layer thickness in the pectin-fed rats. In addition, the mucosa tended to be thicker in the pectin-fed rats, though the difference was only significant in segment $c$.

Within the mucosa the striking finding was the increase in crypt depth in the pectin-fed rats, which was highly significant in segments $\mathrm{c}$ and $\mathrm{e}$. Villous height showed less variation, the only significant difference being that the villi of the pellet-fed rats were shorter in segment $c$ than those of either pectin- or basal-diet-fed rats.

Apart from a difference in villous height in segment $c$, there were no significant differences between basal- and pellet-diet-fed rats in any measurement. 
Table 3. Total intestinal wall thickness, muscle layer thickness, mucosal thickness, crypt depth and villous height $(\mu \mathrm{m})$ in three groups of rats fed on a basal, pectin or pellet diet $\dagger$

(Mean values with their standard errors for groups of rats fed on basal, pectin or pellet diets. Values in parentheses show for each segment the number of animais from whom histological measurements were made)

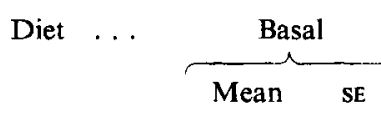

Segment a Muscle

Mucosa

Crypt

Villus

Total

Segment c

Muscle

Mucosa

Crypt

Villus

Total

Segment e

Muscle

Mucosa

Crypt

Villus

Total
(6)

$\begin{array}{rr}151 & 60 \\ 585 & 28 \\ 223 & 28 \\ 362 & 7 \\ 778 & 55\end{array}$

(6)

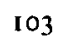

537

174

364

678

(5)

$\begin{array}{ll}\text { I I I } & 45^{*} \\ 444 & 13 \\ \text { I79 } & 10^{* *} \\ 265 & \text { I } 6\end{array}$

$598 \quad 18^{*}$

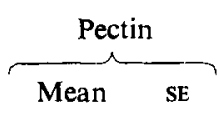

(6)

$\begin{array}{rr}111 & 11 \\ 608 & 13 \\ 244 & 9 \\ 364 & 16 \\ 765 & 24\end{array}$

(5)

$\begin{array}{ll}141 & 48 \\ 674 & 42 \\ 262 & 20 \\ 428 & 34 \\ 854 & 47\end{array}$

(6)

$\begin{array}{ll}172 & 51 \\ 486 & 24 \\ 238 & 17 \\ 248 & 20 \\ 702 & 32\end{array}$

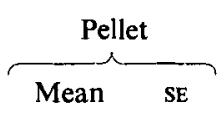

(4)

$\begin{array}{ll}146 & 57 \\ 550 & 71 \\ 229 & 32 \\ 321 & 47 \\ 745 & 74\end{array}$

(5)

$\begin{array}{rc}59 & 4 \\ 507 & 20^{* *} \\ 169 & 7^{* * *} \\ 318 & 10^{* * *} \\ 605 & 17^{* * *}\end{array}$

(6)

$\begin{array}{rc}74 & 33^{* * *} \\ 454 & 33 \\ 172 & 6^{* *} \\ 282 & 30 \\ 565 & 30^{* *}\end{array}$

Differences between either the basal- or pellet-diet-fed groups and the pectin-fed group were statistically significant: $* P<0.05, * * P<0.01, * * * P<0.005$.

$\dagger$ For details, see p. 358 .

\section{Small-bowel mucosal biochemistry}

Mucosal DNA content $(\mu \mathrm{g} / \mathrm{mm}$ intestine) was similar in all three dietary groups for all three intestinal segments (Table 4 ).

Mucosal protein $(\mu \mathrm{g} / \mathrm{mm}$ intestine) tended to be greater in the pectin-fed rats, though only in segment $\mathrm{c}$ was the protein content significantly greater than in the basal-diet-fed group $(P<0.05)$, and only in segment a was it significantly greater than in the pellet-dietfed group $(P<0.01)$.

There was a striking reduction in the specific activity of both alkaline phosphatase and leucyl- $\beta$-naphthylamidase (units/mg DNA) in the upper jejunum (segment a) from the pectin-fed rats, compared with the rats given either the basal or pellet diet. These differences were also seen when the enzyme specific activity was expressed per mg mucosal protein. These differences were not so marked in either the mid-jejunum (segment $c$ ) or in the terminal ileum (segment e). The specific activity of leucyl- $\beta$-naphthylamidase showed no significant difference between the three groups of rats for these two distal intestinal segments. Some differences were seen for alkaline phosphatase (Table 4 ) but the activity of this enzyme was always very much lower in these two distal segments than in the upper jejunum. The rapid 'fall off' in alkaline phosphatase specific activity down the bowel length, and the maintenance of leucyl- $\beta$-naphthylamidase activity are in agreement with the work of others (Gleeson, Dowling et al. 1972). 
Table 4. Mucosal DNA and protein content $(\mu \mathrm{g} / \mathrm{mm}$ intestine), alkaline phosphatase (EC 3.I.3.I) and $\beta$-leucyl naphthylamidase (EC 3.4.II.I) activity (units/mg DNA) in three groups of rats fed on a basal, pectin or pellet diet $\dagger$

(Mean values with their standard errors for groups of six rats fed basal and pectin diets and five rats fed on the pellet diet)

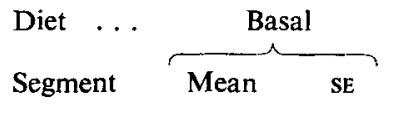

$\begin{array}{lll}\mathrm{a} & 18.9 & 2.0 \\ \mathrm{c} & 21.6 & 2.2 \\ \mathrm{e} & 10.0 & 2.0\end{array}$

$\begin{array}{lll}\text { a } & 32 I & 43 \\ \text { c } & 336 & 37 \\ \text { e } & 197 & 35\end{array}$

$\begin{array}{rrr} & & \\ \text { a } & 175.0 & 56.7^{*} \\ \text { e } & 19.3 & 6.3^{*} \\ & 5.6 & 0.8\end{array}$

\begin{tabular}{crc} 
& \multicolumn{2}{c}{ L } \\
c & 195.8 & $37.4^{* * *}$ \\
e & 126.2 & 14.4 \\
$71 \cdot 0$ & 7.0
\end{tabular}

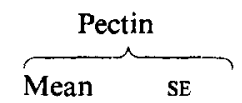

Mucosal DNA

$\begin{array}{ll}\text { I9.7 } & 2.4 \\ 20.9 & 2.6\end{array}$

$14.8 \quad 1.9$

\section{Mucosal protein}

$\begin{array}{ll}381 & 27 \\ 443 & 19 \\ 262 & 36\end{array}$

Alkaline phosphatase

$\begin{array}{rl}54 \cdot 8 & 8 \cdot 0 \\ 7 \cdot 0 & 1 \cdot 5 \\ 4 \cdot 2 & 0 \cdot 4\end{array}$

Leucyl- $\beta$-naphthylamidase

$\begin{array}{rr}52.2 & 13.4 \\ 115.2 & 12.9 \\ 61.1 & 10.2\end{array}$

\begin{tabular}{|c|c|}
\hline \multicolumn{2}{|c|}{ Pellet } \\
\hline Mean & SE \\
\hline $16 \cdot 3$ & I. 6 \\
\hline 18.9 & $2 \cdot 8$ \\
\hline 12.6 & $2 \cdot 3$ \\
\hline 283 & $12^{* *}$ \\
\hline 375 & 35 \\
\hline $20 I$ & 34 \\
\hline
\end{tabular}

$\begin{array}{rl}118 \cdot 9 & 44 \\ 10 \cdot 0 & 5 \cdot 2 \\ 2 \cdot 2 & 0.3^{* * *}\end{array}$

$\begin{array}{rl}112 \cdot 8 & 22 \cdot 2 * * * \\ 227 \cdot 2 & 68 \cdot 0 \\ 87 \cdot 4 & 23 \cdot 7\end{array}$

Differences between either the basal- or pellet-diet-fed groups and the pectin-fed group were statistically significant: ${ }^{*} P<0.05,{ }^{* *} P<0.0 \mathrm{I},{ }^{* * *} P<0.005$.

$\dagger$ For details, see p. 358 .

Table 5. Glucose absorption ( $\mu \mathrm{mol} / \mathrm{mm}$ intestine per $h$ ) from in vivo intestinal loops in three groups of rats fed on a basal, pectin or pellet diet*

(Mean values with their standard errors for groups of five rats fed on basal and pellet diets and for six rats fed on the pectin diet)

\begin{tabular}{ccccc} 
Diet $\ldots .$. & \multicolumn{2}{c}{ Pectin } \\
Segment & Mean & SE & Mean & SE \\
b & I.08 & 0.12 & I.27 & 0.13 \\
d & I.10 & 0.14 & I.09 & 0.14 \\
& & $*$ For details, see p. 358.
\end{tabular}

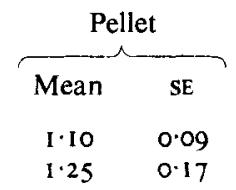

Apart from a difference in alkaline phosphatase in segment $e$, there were no significant differences in mucosal biochemistry between basal- and pellet-diet-fed rats.

\section{Glucose absorption}

There were no significant differences in glucose absorption from either segment $b$ or $d$ between the three dietary groups (Table 5).

Our values for glucose abosrption from the jejunal loop (segment b) are similar to those of other workers (Gleeson, Cullen et al. 1972). Our values for absorption from the more distal segment $\mathrm{d}$ are higher than those of Gleeson, Cullen et al. (1972) probably because our loop was more proximal than their terminal ileal segment. 
Table 6. Weights of stomach and caecum plus colon $(\mathrm{g})$, in three groups of rats fed on a basal, pectin or pellet diet $\dagger$

(Mean values with their standard errors for groups of six rats fed on basal and pectin diets and for five rats fed on the pellet diet)

\begin{tabular}{|c|c|c|c|c|c|c|}
\hline \multirow[t]{2}{*}{ Diet } & \multicolumn{2}{|c|}{ Basal } & \multicolumn{2}{|c|}{ Pectin } & \multicolumn{2}{|c|}{ Pellet } \\
\hline & Mean & SE & Mean & SE & Mean & SE \\
\hline Stomach & $I \cdot 2 I$ & 0.04 & $I \cdot 29$ & 0.07 & $I \cdot 66$ & $0.05^{* * *}$ \\
\hline Caecum and colon & $I \cdot 63$ & $0 . I^{* * *}$ & $2 \cdot 89$ & 0.2 & $2 \cdot 24$ & $0 . I^{* *}$ \\
\hline
\end{tabular}

Differences between either the basal- or pellet-diet-fed groups and the pectin-fed group were statistically significant: ${ }^{* *} P<0.01,{ }^{* * *} P<0.005$.

$\dagger$ For details, see p. 358 .

Anatomy of stomach and large bowel

The stomach was significantly heavier in the pellet-diet-fed rats than in either pectin- or basal-diet-fed rats. The large bowel was significantly heavier in pectin-diet-fed rats than in either pellet- or basal-diet-fed rats (Table 6).

\section{DISCUSSION}

The dietary content of pectin used in these studies may be considered high ( $180 \mathrm{~g} / \mathrm{kg} \mathrm{diet}$ ) but is similar to that used in other studies (Ershoff, 1974; Cullen \& Oace, 1978). A I80 g pectin $/ \mathrm{kg}$ diet was chosen to give a dietary fibre content similar to that of the pellet diet. No dietary fibre measurements are available for the pellet diet, but the crude fibre content of $5 \mathrm{I} \mathrm{g} / \mathrm{kg}$ suggests a dietary fibre content of $100-200 \mathrm{~g} / \mathrm{kg}$. The pectin content of the pellet diet is also unknown, but published values suggest that it is unlikely to be high. Therefore the fact that we have found significant differences in morphology and biochemistry between the small bowels of the pectin-diet-fed rats compared with those of both the pellet-and basal-diet-fed rats strongly suggests that the differences observed are due to the pectin. The pectin content of the experimental diet is also not entirely dissimilar from that used in man. The dry weight of a human diet is approximately $500 \mathrm{~g} / \mathrm{d}$ so that a pectin dose of $35 \mathrm{~g} / \mathrm{d}$ (Jenkins et al. I975; Miettinen \& Tarpila, 1977) represents $70 \mathrm{~g} / \mathrm{kg}$ dry weight.

The differences between the small bowel of the pectin-fed rats and those of the other two dietary groups were both in the muscle layer and in the mucosa. The caecum and colon were also heavier in the pectin-fed rats. One possible explanation for the increased musclelayer thickness in the mid-jejunum and terminal ileum, and for the increased colonic weight of the pectin-fed rats, is that pectin is having a 'bulking' effect. Pectin forms a viscous gel when mixed with water, and the increased work of propelling this along the bowel might lead to muscle hypertrophy. However, although previous workers feeding a variety of bulking materials have all found an increase in colonic size, they have found little or no change in small bowel dimensions (Addis, 1932; Wierda, 1950; Fischer, 1957; Dowling et al. 1967). Furthermore, pectin is virtually completely metabolized within the bowel by micro-organisms and causes only modest increases in stool weight, so that even the changes in the colon may not be due to a bulking effect.

The alterations within the small-bowel mucosa of the pectin-fed rats are difficult to interpret. The mucosal thickness, the weight of mucosal scrapings and the mucosal DNA content were all greater in the pectin-fed rats though the differences were not always statistically significant. The more constant and striking change in the mucosa was the increased crypt depth of the pectin-fed rats, which was significant in both mid-jejunum and terminal ileum. Villous height varied much less, the only significant difference being a 
greater villous height in the mid-jejunal segment of the pectin-fed rats compared with the pellet-diet-fed rats. The increased crypt depth was associated with decreased brush border enzyme activity in the pectin-fed rats. There was a reduction both in the total enzyme content (units/mm intestine) and in the enzyme activity expressed per mg DNA, and the decrease was greater in the upper and mid-jejunal segments. These findings could be explained by increased epithelial cell turnover in the pectin-fed rats, resulting in crypt hyperplasia, and less mature enterocytes with lower enzyme content forming the villi (Nordström \& Dahlqvist, 1973). Further studies of epithelial cell kinetics are required to confirm this hypothesis. The fact that the histological changes are more marked in the distal segments of bowel might suggest that the agent responsible for the increased turnover is one of the products of bacterial breakdown of pectin. However, we have found the greatest changes in enzyme activity in the proximal bowel, so that the possibility remains that pectin itself might be the agent responsible. A third possibility is that pectin feeding alters the bacterial flora of the rat small bowel (Cullen \& Oace, 1978).

Despite the difficulties inherent in making linear measurements on histological sections of small bowel (Dunnill \& Whitehead, 1972) the close similarities between both the morphological and functional measurements in the basal diet and pellet-diet-fed rats make it unlikely that the differences seen in the pectin-fed rats were due to artefact. In particular, the increased length of the unfixed small bowel in the pectin-fed rats is unlikely to be due to longitudinal stretching as both the wet weight of unfixed segments of bowel and the thickness of the muscle layers in fixed histological sections are greater in the pectin-fed rats. This increase in small-bowel length taken together with the tendency for villous height to be greater in the pectin-fed rats suggests that these rats will have an increased absorptive surface area. This may explain the more rapid absorption of paracetamol demonstrated previously (Brown et al. 1979). It is relevant here that the absorptive capacity of the bowel as measured by glucose absorption is not altered in the pectin-fed rats.

With only two minor exceptions, we have found no significant difference in any of the morphological, biochemical or functional measurements between the small bowels of the rats fed on the fibre-free basal diet, and those fed on the standard laboratory pelleted diet. The lack of effect of the pellet diet confirms previous reports using other forms of fibre (Addis, 1932; Fischer, 1957). However, Younoszai et al. (1978) found that both a pellet diet and a synthetic diet with added cellulose or oats enhanced growth of the small intestine compared with synthetic diet alone. Possible explanations of the difference between our findings and those of Younoszai et al. (1978) are, first that they used weanling rats (bodyweight 50-80 g) whereas we used adult rats (body-weight I 80-220 g), secondly that our study period was longer (12-15 weeks $v$. 5 weeks), and thirdly that the composition of the two pellet diets differed, particularly in respect of dietary fibre source.

The effect of pectin on human bowel morphology requires further investigation.

\section{REFERENCES}

Addis, T. (1932). Am. J. Physiol. 99, 417.

Brown, R. C., Kelleher, J., Walker, B. E. \& Losowsky, M. S. (I979). Br. J. Nutr. 4I, 455.

Cullen, R. W. \& Oace, S. M. (1978). J. Nutr. ro8, 640.

Dowling, R. H., Riecken, E. O., Laws, J. W. \& Booth, C. C. (1967). Clin. Sci. 32, I.

Dunnill, M. S. \& Whitehead, R. (1972). J. clin. Path. 25, 243.

Ershoff, N. H. (1974). Am. J. clin. Nutr. 27, 1395.

Fischer, J. E. (1957). Am. J, Physiol. 188, 550.

Gleeson, M. H., Cullen, J. \& Dowling, R. H. (1972). Clin. Sci. 43, 731.

Gleeson, M. H., Dowling, R. H. \& Peters, T. J. (1972). Clin. Sci. 43, 743.

Hatcher, D. W. \& Goldstein, G. (1969). Analyt. Biochem. 31, 42.

Hyden, S. (1956). K. LantbrHögsk. Annlr 22, $41 \mathrm{I}$.

Jenkins, D. J. A., Leeds, A. R., Newton, C. \& Cummings, J. H. (I975). Lancet i, I I 6.

Kay, R. M. \& Truswell, A. S. (1977). Am. J. clin. Nutr. 30, 171. 
Krebs, H. A. \& Henseleit, K. (1932). Hoppe-Seyler's Z. Physiol. Chem. 210, 33.

Leveille, G. A. \& Sauberlich, H. E. (1966). J. Nutr. 88, 209.

Lowry, O. H., Rosebrough, N. J., Farr, A. L. \& Randall, R. J. (1951). J. biol. Chem. 193, 265.

Miettinen, T. A. \& Tarpila, S. (1977). Clinica chim. Acta 79, 471.

Nordström, C. \& Dahlquist, A. (1973). Scand. J. Gastroenterol. 8, 407.

Peters, T. J., Müller, M. \& de Duve, C. (I972). J. exp. Med. 136, 1117.

Sheff, M. F. \& Smyth, D. H. (1955). J. Physiol., Lond. 128, 67 P.

Truswell, A. S. (1977). Nutr. Rev. 35, 51.

Wierda, J. L. (1950). Anat. Rec. 107, 221.

Younoszai, M. K., Adedoyin, M. \& Ranshaw, J. (1978). J. Nutr. ro8, 34 I. 